\title{
Equity in human papilloma virus vaccination uptake?: sexual behaviour, knowledge and demographics in a cross-sectional study in (un)vaccinated girls in the Netherlands
}

Madelief Mollers ${ }^{1,2 \dagger}$, Karin Lubbers ${ }^{3 \dagger}$, Symen K Spoelstra ${ }^{3}$, Willibrord CM Weijmar-Schultz ${ }^{3}$, Toos Daemen ${ }^{4}$, Tjalke A Westra ${ }^{4}$, Marianne AB van der Sande ${ }^{1,5}$, Hans W Nijman ${ }^{3}$, Hester E de Melker ${ }^{1}$ and Adriana Tami ${ }^{4,6^{*}}$

\begin{abstract}
Background: In the Netherlands, human papillomavirus (HPV) vaccination is part of a national program equally accessible for all girls invited for vaccination. To assess possible inequalities in vaccine uptake, we investigated differences between vaccinated and unvaccinated girls with regard to various characteristics, including education and ethnicity, (both associated with non-attendance to the national cervical screening program), sexual behaviour and knowledge of HPV.
\end{abstract}

Methods: In 2010, 19,939 nationwide randomly-selected 16-17 year-old girls (2009 vaccination campaign) were invited to fill out an online questionnaire. A knowledge scale score and multivariable analyses identified variables associated with vaccination status.

Results: 2989 (15\%) of the selected girls participated (65\% vaccinated, 35\% unvaccinated). The participants were comparable with regard to education, ethnicity, most sexual risk behaviour and had similar knowledge scores on HPV transmission and vaccination. However, unvaccinated girls lived in more urbanised areas and were more likely to have a religious background. Irrespective of vaccination status, $81 \%$ of the girls were aware of the causal relationship between HPV and cervical cancer, but the awareness of the necessity of cervical screening despite being vaccinated was limited.

Conclusions: HPV vaccine uptake was not associated with knowledge of HPV and with factors that are known to be associated with non-attendance to the cervical cancer screening program in the Netherlands. Furthermore, most sexual behaviour was not related to vaccination status meaning that teenage unvaccinated girls were not at a disproportionally higher risk of being exposed to HPV. Routine HPV vaccination may reduce the social inequity of prevention of cervical cancer.

Keywords: Monitoring, Human papilloma virus, Vaccination uptake, Sexual behaviour, Knowledge

\section{Background}

Human papillomavirus (HPV) infection is one of the most common sexually transmitted infections (STI) worldwide. By the age of 50 , about $80 \%$ of sexually active women will acquire HPV [1-3]. Most infections are transient

\footnotetext{
*Correspondence: a.tami@umcg.nl

${ }^{\dagger}$ Equal contributors

${ }^{4}$ Department of Medical Microbiology, Molecular Virology Section, University of Groningen, University Medical Center Groningen, Groningen, The Netherlands

${ }^{6}$ Department of Medical Microbiology, University Medical Center Groningen P.O. Box 30.001, 9700 RB Groningen, The Netherlands

Full list of author information is available at the end of the article
}

and around 90\% clears within two years [4,5]. However, a persisting high-risk HPV infection is the most important risk factor for the development of premalignant cervical intraepithelial neoplasia (CIN1-3) and cervical cancer [6].

Since 2006, a quadrivalent vaccine that induces protection against HPV types 6, 11, 16 and $18\left(\right.$ Gardasil $\left.^{\circ}\right)$, and in 2007 a bivalent vaccine against HPV type 16 and 18 (Cervarix $\left.{ }^{\circ}\right)$ are available. Both have shown an efficacy of $>90 \%$ in preventing CIN2/3 [7,8].

In the Netherlands, the bivalent HPV vaccine (Cervarix $\left.{ }^{\circ}\right)$ targeting 12-year-old girls became part of the National 
Immunisation Program in 2010. In 2009, girls aged 13 to 16 years were offered this vaccine during a "catch-up" vaccination program where the uptake amounted to 52\% [9]. $\mathrm{HPV}$ vaccination uptake depends on diverse factors. In the United Kingdom, schoolgirls from ethnic minorities had a lower vaccine uptake and in the United States, girls with lower socio-economic status were less likely to take up the full 3 doses of the vaccine [10,11]. In the Netherlands, a cervical cancer screening program runs since 1976. Currently, the program provides organized cervical cytological screening every five years for women aged 30-60 years. In 2005 , there was a $65 \%$ attendance to the cervical screening program [12]. However, when including opportunistic screening figures, the overall coverage for cervical screening amounted to $77 \%$ nationwide [13]. It has been shown that in the Netherlands, socio-economically disadvantaged women and women of non-Dutch nationality attend the national cervical screening program less frequently [14]. More than half of the cervical cancers are diagnosed in women who do not attend the Dutch screening program $[15,16]$. Reducing the occurrence of cervical cancer might thus be hampered if girls who tend to decline HPV vaccination now are also screened less often in the future. This might lead to inequity, i.e. unequal fairness or justice in the way people are treated.

Prior to introduction of vaccination, some studies have reported on girls' intention to be vaccinated [17-19]. However, little is known about the characteristics of girls in relation to actual HPV vaccination uptake [20,21]. This study aims to explore differences between vaccinated and unvaccinated girls with regard to characteristics such as education, ethnicity, (sexual) risk behaviour and knowledge of HPV. Understanding the features of these two groups could provide insight in future vaccine and screening targeting efforts.

\section{Methods}

\section{Study population and study design}

A nationwide self-reported cross-sectional study of 1617-year-old girls was performed in the Netherlands in December 2010. A random sample of 19,939 girls born in 1993, invited for the HPV catch-up vaccination campaign in 2009 (9992 vaccinated and 9947 unvaccinated), was selected from the national vaccination database (Praeventis) held at the National Institute for Public Health and the Environment (RIVM) [22].

A semi-structured questionnaire was developed, pretested and applied to the study population via online research survey software (EFS Survey version 8.1, Unipark (Questback)). The questionnaire contained pre-coded questions on the following topics: Socio-demographic: education level (girl and parents), ethnicity (Dutch, Turkish, Moroccans, Surinamese, Antilleans, Arubans and other), religion, alcohol and smoking behaviour. Sexual behaviour: e.g. ever have had sexual contact (vaginal or anal), age of sexual debut, use of contraceptives (especially condom use), number of sexual partners, type of current partner (steady/ casual) and history of STI. HPV knowledge and HPV vaccination: e.g. modes of transmission, protection level of $\mathrm{HPV}$ vaccination, risk of infection and participation in the cervical cancer screening program. Each girl selected for the study received an invitation by post with an information letter for the girl and one for her parents/caretakers, and a link and a unique code to access the online questionnaire. The questionnaire took approximately ten minutes to fill out and the information was processed anonymously.

This research was performed according to the principles contained in the Declaration of Helsinki [23]. The Dutch Central Committee on Research Involving Human Subjects (Centrale Commissie Mensgebonden Onderzoek (CCMO)) decided that the nature of the study did not require mandatory approval of a competent medical-ethical review committee, in agreement with the Dutch Medical Research involving Human Subjects Act. The CCMO allowed to receive consent from the participating girls through the online system (no written consent from the girls or their parents was required).

\section{Statistical analysis}

Differences in socio-demographic characteristics, sexual behaviour and knowledge of HPV between vaccinated and unvaccinated women were compared in contingency tables using $\chi^{2}$ test. Socio-economic status was also assessed using the 'status score' computed by the Dutch Institute for Social Research (SCP, www.scp.nl), as a proxy for socioeconomic status (SES). This score takes into account the average income per household in a given postcode area as well as the percentage of households with low income, without a paid job and with low education level. The lower the score is, the higher the socioeconomic status [24]. Knowledge scale composite scores were calculated assigning a point for each correct answer to 8 general knowledge questions (0-8) (general knowledge score) and to 10 questions on HPV transmission knowledge (0-10) (transmission knowledge score). Mean scores were compared for vaccinated and unvaccinated girls by a t-test. Significance was determined at the $5 \%$ level (P-value $\leq 0.05$ ).

Variables associated with vaccination status found to approach significance ( $\mathrm{P}$-value $\leq 0.1$ ) were fitted in a multivariable logistic regression model. The strength of the associations was expressed as crude odds ratios (OR) in univariable analysis and as adjusted OR (aOR) in multivariable analysis, comparing vaccinated vs. unvaccinated girls. Two models were carried out: one including the total sample of girls and the second comprising only sexually active girls. The final models included those factors that remained significant (P-value $\leq 0.05$ ) after backward selection and those 
found to change the OR of other variables by at least $10 \%$. Analyses were conducted using software packages from SAS 9.2 (SAS Institute Inc. 2010, USA).

\section{Results}

Socio-demographic and sexual behaviour characteristics A total of 2989 females (15\% of invited participants) aged 16-17 (median 17) participated in this study. Among them, 65\% received at least $1 \mathrm{HPV}$ vaccination and 35\% received none. The distribution of most characteristics was similar between vaccinated and unvaccinated girls (Tables 1 and 2). However, vaccinated girls were more likely to live in low urbanised areas and less likely had a religious background. Amongst those who professed a religion, vaccinated girls were more often Catholic while unvaccinated girls were more often Protestant Christian. The vaccination status between the different non-Dutch ethnic subgroups was similar $(\mathrm{P}=0.833)$, they were therefore grouped together into a "non-Dutch" ethnic group for analysis. Ethnicity was not associated with vaccination status (Table 1). Drinking alcohol was reported more by vaccinated girls as was the use of contraceptives (Table 1). A slightly higher percentage of vaccinated girls were sexually active but amongst them a lower mean total number of sexual partners in their lifetime was identified. Except for the higher percentage of female partners in the unvaccinated girls, there were no other differences in sexual behaviour (Table 2).

\section{Sexual behaviour and views associated with HPV vaccination}

The majority of both vaccinated and unvaccinated girls (97.3\% vs. 98.2\%) thought that HPV vaccination had not changed their sexual behaviour, $0.8 \%$ of the girls answered that use of condoms would not be needed to protect against STIs after HPV vaccination. However, $17 \%$ of the vaccinated and $26 \%$ of the unvaccinated replied that other girls would be inclined to use less condoms after vaccination. In addition, a higher proportion of vaccinated girls thought HPV could not be transmitted when using condoms.

\section{General knowledge of HPV and HPV vaccination}

Vaccinated girls were less aware that HPV vaccination does not protect against all HPV types, but were more aware that HPV vaccination does not protect against all STIs (Table 3). In general, few girls knew that HPV may cause genital warts $(20 \%)$ and that most HPV infections clear on their own (5\%). Approximately three quarters (73\%) were aware that unprotected sex entails a higher risk of acquiring an HPV infection. More than $80 \%$ recognised that an HPV infection is a risk for cervical cancer and about $68 \%$ of the girls knew that an HPV infection does not always lead to cervical cancer. Also more than $80 \%$ knew that cervical cancer does not always lead to death. Depending on the question, a variable number of girls (9\% to 63\%) answered 'don't know'. The general knowledge score (one point for every right answer) was similar between vaccinated and unvaccinated girls.

\section{Cervical screening}

Vaccinated girls reported more often that their mother participated in the cervical cancer screening program, and that it would still be necessary to participate in such a program after being vaccinated. However, they were less aware of the existence of this program (Table 3).

\section{Knowledge on HPV infectiousness}

Most girls were familiar with the association between unsafe vaginal sex and transmission of HPV. This knowledge was lower for other forms of sex, such as unsafe anal or oral sex. A low proportion knew that HPV could be transmitted via skin-to-skin contact or by stroking their partner's genitals (Table 4). The HPV transmission knowledge score also showed no difference in univariable analysis.

\section{Multivariable analysis of predictors for vaccine receipt}

Variables whose association with vaccination status approached significance ( $\mathrm{P}$-value $\leq 0.1$ ) were fitted in a multivariable logistic regression model (Table 5). The factors that remained independently associated with being vaccinated were living in low urbanised areas, consuming alcohol, not being sexually active, using contraceptive methods and not being aware of the cervical cancer screening program. Additionally, girls ascribing to no religion and those who professed a Catholic faith were more likely to be vaccinated than those that were either Protestant or who belonged to another religion. Vaccinated girls were also more likely to report that their mothers participated in the cervical cancer screening program or not knowing their mother's participation status in this screening program.

Furthermore, considering perceptions of HPV, vaccinated girls thought more often that HPV vaccination protects against all HPV types and were less likely to think that girls would use condoms less frequently once vaccinated. Interestingly, more unvaccinated girls did not know that condoms were still needed after vaccination.

\section{Discussion}

This population-based study is one of the first that examined actual determinants for individual vaccine uptake instead of willingness to be vaccinated. Vaccinated and unvaccinated girls were comparable with regard to education, education of parents, ethnicity, most sexual risk behaviour and had similar scores on knowledge of HPV infection and HPV transmission. They differed with 
Table 1 Socio-demographic characteristics amongst all girls participating in our study ( $\mathrm{n}=2989$ ), the Netherlands 2010

\begin{tabular}{|c|c|c|c|c|c|}
\hline Category & $\begin{array}{l}\text { Total } \\
\text { N (\%) }\end{array}$ & $\begin{array}{c}\text { Vaccinated } \\
\text { n (\%) }\end{array}$ & $\begin{array}{c}\text { Unvaccinated } \\
\text { n (\%) }\end{array}$ & $\begin{array}{l}\mathrm{OR}(95 \% \mathrm{Cl}) \text { for } \\
\text { being vaccinated }\end{array}$ & P-value \\
\hline & $2989(100)$ & $1938(65)$ & $1051(35)$ & & \\
\hline Age & & & & ref & \\
\hline Median (range) & $17(16-17)$ & $17(16-17)$ & $17(16-17)$ & $0.9(0.6-1.2)$ & 0.45 \\
\hline \multicolumn{6}{|l|}{ Ethnicity $(n=2988)$} \\
\hline Dutch & $2849(95)$ & $1852(96)$ & $997(95)$ & ref & \\
\hline Non-Dutch & $139(5)$ & $86(4)$ & $53(5)$ & $0.9(0.6-1.2)$ & 0.45 \\
\hline \multicolumn{6}{|c|}{ Degree of urbanisation $(n=2971)$} \\
\hline Low (1-1000 inhabitants) & $1514(51)$ & $1019(53)$ & $495(47)$ & ref & \\
\hline High (>1000 inhabitants) & $1457(49)$ & $908(47)$ & $549(53)$ & $0.8(0.7-0.9)$ & 0.004 \\
\hline \multicolumn{6}{|c|}{ Socio economic status ${ }^{\mathbf{a}}(\mathrm{n}=2962)$} \\
\hline Mean $(95 \% \mathrm{Cl})$ & $-0.01(-0.03-0.03)$ & $-0.02(-0.06-0.02)$ & $0.02(-0.03-0.07)$ & $0.9(0.9-1.0)$ & 0.20 \\
\hline \multicolumn{6}{|l|}{ Religion ( $n=2898)$} \\
\hline No religion & $1532(53)$ & $1050(56)$ & $482(48)$ & ref & \\
\hline Catholics & $708(24)$ & $511(27)$ & $197(19)$ & $1.2(1.0-1.5)$ & \\
\hline Protestant Christian & $642(22)$ & $317(17)$ & $325(32)$ & $0.4(0.4-0.5)$ & \\
\hline Other & $16(1)$ & $6(0.3)$ & $10(1)$ & $0.3(0.1-0.7)$ & $<0.001$ \\
\hline \multicolumn{6}{|l|}{ Education $^{b}$} \\
\hline Low & $221(7)$ & $148(8)$ & $73(7)$ & ref & \\
\hline Middle & $992(33)$ & $631(33)$ & $361(34)$ & $0.9(0.6-1.2)$ & \\
\hline High & $1776(59)$ & $1159(60)$ & $617(59)$ & $0.9(0.7-1.2)$ & 0.54 \\
\hline \multicolumn{6}{|c|}{ Education of parents ${ }^{\mathbf{b}}(n=2787)$} \\
\hline Low & $49(2)$ & $28(2)$ & $21(2)$ & ref & \\
\hline Middle & $1162(42)$ & $749(41)$ & $413(42)$ & $1.4(0.8-2.4)$ & \\
\hline High & $1576(57)$ & $1031(57)$ & $545(56)$ & $1.4(0.8-2.5)$ & 0.45 \\
\hline \multicolumn{6}{|l|}{ Alcohol use ( $n=2983)$} \\
\hline No & $723(24)$ & $425(22)$ & $298(28)$ & ref & \\
\hline Yes & $2260(76)$ & $1509(78)$ & $751(72)$ & $1.4(1.2-1.7)$ & $<0.001$ \\
\hline \multicolumn{6}{|l|}{ Smoking $(n=2984)$} \\
\hline No & $2280(76)$ & $1492(77)$ & $788(75)$ & ref & \\
\hline Current smoker & $476(16)$ & $299(15)$ & $177(17)$ & $0.9(0.7-1.2)$ & \\
\hline Former smoker & $228(8)$ & $144(7)$ & $84(8)$ & $0.9(0.7-1.1)$ & 0.47 \\
\hline \multicolumn{6}{|l|}{ Contraception $(n=2910)$} \\
\hline No & $902(31)$ & $533(28)$ & $369(37)$ & ref & \\
\hline Yes & $2008(69)$ & $1371(72)$ & $637(63)$ & $1.5(1.3-1.8)$ & $<0.001$ \\
\hline \multicolumn{6}{|c|}{ Type of contraception $(n=2003)$} \\
\hline Pill & $1253(63)$ & $848(62)$ & $405(64)$ & ref & \\
\hline Condom & $160(8)$ & $100(7)$ & $60(9)$ & $0.8(0.6-1.1)$ & \\
\hline Pill and condom & $544(27)$ & $385(28)$ & $159(25)$ & $1.2(0.9-1.4)$ & \\
\hline Other & $46(2)$ & $34(2)$ & $12(2)$ & $1.4(0.7-2.7)$ & 0.18 \\
\hline \multicolumn{6}{|l|}{ Ever had sex ( $n=2898)$} \\
\hline No & $1303(45)$ & $826(44)$ & $477(48)$ & ref & \\
\hline Yes & $1595(55)$ & $1070(56)$ & $525(52)$ & $1.2(1.0-1.4)$ & 0.04 \\
\hline
\end{tabular}

${ }^{a}$ Combination of the average income per household with percentage of households with low income, without a paid job and with low average education resulting in a score ranging $[-4 ;+4]$. Note that the lower the score is, the higher the socioeconomic status is [24].

${ }^{b}$ Low $=$ no education or primary education; Middle = junior technical school, lower general or intermediate vocational secondary education; High $=$ higher vocational or higher general secondary education, pre-university/university education.

Missing values are deducted from the total number of girls. 
Table 2 Sexual risk factors amongst sexually active girls participating in our study $(\mathbf{n}=1595)$, the Netherlands 2010

\begin{tabular}{|c|c|c|c|c|c|}
\hline Category & $\begin{array}{l}\text { Total } \\
\text { N (\%) }\end{array}$ & $\begin{array}{l}\text { Vaccinated } \\
\text { n (\%) }\end{array}$ & $\begin{array}{c}\text { Unvaccinated } \\
\text { n (\%) }\end{array}$ & $\begin{array}{l}\text { OR }(95 \% \mathrm{Cl}) \text { for } \\
\text { being vaccinated }\end{array}$ & P-value \\
\hline & $1595(100)$ & $1070(67)$ & $525(33)$ & & \\
\hline \multicolumn{6}{|c|}{ Steady partner $(n=1588)$} \\
\hline No & $510(32)$ & $336(32)$ & $174(33)$ & ref & \\
\hline Yes & $1078(68)$ & $729(68)$ & $349(67)$ & $1.1(0.9-1.4)$ & 0.49 \\
\hline \multicolumn{6}{|c|}{ Number of casual partners $(n=1589)$} \\
\hline 0 & $806(51)$ & $553(52)$ & $253(48)$ & ref & \\
\hline 1 & $602(38)$ & $402(38)$ & $200(38)$ & $0.9(0.7-1.2)$ & \\
\hline 2 & $125(8)$ & $75(7)$ & $50(10)$ & $0.7(0.5-1.0)$ & \\
\hline$>2$ & $56(4)$ & $35(3)$ & $21(4)$ & $0.8(0.4-1.4)$ & 0.24 \\
\hline \multicolumn{6}{|c|}{ Condom use steady partner $(n=1078)$} \\
\hline Always & $193(18)$ & $126(17)$ & $67(19)$ & ref & \\
\hline Not always & $885(82)$ & $603(83)$ & $282(81)$ & $1.1(0.8-1.6)$ & 0.44 \\
\hline \multicolumn{6}{|c|}{ Condom use casual partner $(n=778)$} \\
\hline Always & $219(28)$ & $144(28)$ & $75(28)$ & ref & \\
\hline Not always & $559(72)$ & $364(72)$ & $195(72)$ & $1.0(0.7-1.3)$ & 0.87 \\
\hline \multicolumn{6}{|l|}{ STI $(n=780)$} \\
\hline No & $641(82)$ & $423(83)$ & $218(80)$ & ref & \\
\hline Yes & $139(18)$ & $86(17)$ & $53(20)$ & $0.8(0.6-1.2)$ & 0.36 \\
\hline \multicolumn{6}{|c|}{ Sex of partner $(n=1589)$} \\
\hline Male & $1560(98)$ & $1051(99)$ & $509(97)$ & ref & \\
\hline Female & $29(2)$ & $15(1)$ & $14(3)$ & $0.5(0.2-1.1)$ & 0.08 \\
\hline \multicolumn{6}{|c|}{ Age of sexual debut $(n=1579)$} \\
\hline Mean $(95 \% \mathrm{Cl})$ & $15.5(15.4-15.6)$ & $15.5(15.5-15.6)$ & $15.4(15.3-15.5)$ & $1.2(1.0-1.3)$ & 0.74 \\
\hline \multicolumn{6}{|c|}{ Total number of lifetime sexual partners $(n=1584)$} \\
\hline Mean $(95 \% \mathrm{Cl})$ & $2.0(1.9-2.1)$ & $1.9(1.8-2.0)$ & $2.2(2.0-2.4)$ & $0.9(0.9-1.0)$ & $<0.001$ \\
\hline
\end{tabular}

Missing values are deducted from the total number of sexually active girls.

respect to characteristics such as urbanisation degree, religion, contraceptive use, number of lifetime sexual partners and importantly, their opinions on the use of condoms after HPV vaccination and the protection of vaccination against all HPV types.

Studies in the Netherlands have shown that women who are non-Dutch nationals and have a lower socioeconomic status are less likely to participate in the cervical cancer screening program $[14,15]$. These risk factors for non-attendance were not observed in this study for girls who chose not to be vaccinated. We found no relationship between uptake and ethnicity, nor education of the girl or their parents or SES score (both indicators of socio-economic status), which could suggest that the two programs might strengthen each other Another Dutch study also concluded that vaccination and screening (assessed by reported screening behaviour of the mother) complement each other to a large extent [25].

Religion has influenced vaccination decision-making process since the beginning of vaccination efforts [26].
Anti-vaccination proponents were most common in countries with a high proportion of Protestants [27]. In our study, identifying as a Protestant Christian was related to a lower vaccination uptake, as opposed to identifying as a Catholic or not following a religion. In addition to specific religious groups among the Protestant Christians (such as Orthodox reformed), the reluctance towards HPV vaccination might be extended amongst a broader group of Protestant Christians because of the link with a sexually transmitted infection. Participation in screening programs has not been found to be lower in Dutch regions with higher proportion of religious groups [25], highlighting again the possible complementarity between screening and vaccination.

Contradicting results regarding the influence of HPV knowledge and perceptions on vaccination uptake have been reported [28]. Consistent with a Dutch study on acceptance of HPV vaccination [29], we obtained no differences on vaccination uptake with regard to the general HPV knowledge score, nor on the HPV transmission 
Table 3 HPV general knowledge amongst all girls participating in our study $(\mathbf{n}=\mathbf{2 9 8 9})$, the Netherlands 2010

\begin{tabular}{lcccc}
\hline Category & $\begin{array}{c}\text { Total } \\
\mathbf{N}(\%)\end{array}$ & $\begin{array}{c}\text { Vaccinated } \\
\mathbf{n}(\%)\end{array}$ & $\begin{array}{c}\text { Unvaccinated } \\
\mathbf{n}(\%)\end{array}$ & $\begin{array}{c}\text { OR (95\% Cl) for } \\
\text { being vaccinated }\end{array}$ \\
\hline 2989 (100) & $1938(65)$ & $1051(35)$ & \\
HPV vaccination protects against all HPV types $(\mathrm{n}=2910)$ & & & ref \\
No & $1811(62)$ & $1110(58)$ & $701(70)$ & $2.2(1.7-2.9)$ \\
Yes & $373(13)$ & $291(15)$ & $82(8)$ & $1.4(1.2-1.7)$
\end{tabular}

HPV vaccination protects against all STIs $(n=2909)$

$\begin{array}{lcccc}\text { No } & 2567(88) & 1702(89) & 865(86) & \text { ref } \\ \text { Yes } & 52(2) & 33(2) & 19(2) & 0.9(0.5-1.6) \\ \text { Don't know } & 290(10) & 170(9) & 120(12) & 0.7(0.6-0.9)\end{array}$

An HPV infection always leads to cervical cancer $(n=2930)$

$\begin{array}{lcccc}\text { No } & 1984(68) & 1294(68) & 690(68) & \text { ref } \\ \text { Yes } & 121(4) & 80(4) & 41(4) & 1.0(0.7-1.5) \\ \text { Don't know } & 825(28) & 541(28) & 284(28) & 1.0(0.9-1.2)\end{array}$

Cervical cancer is always fatal $(n=2930)$

$\begin{array}{lcccc}\text { No } & 2414(82) & 1579(82) & 835(82) & \text { ref } \\ \text { Yes } & 141(5) & 98(5) & 43(4) & 1.2(0.8-1.8) \\ \text { Don't know } & 375(13) & 238(12) & 137(14) & 0.9(0.7-1.2)\end{array}$

If you have unprotected sex, you are at high risk of an HPV infection ( $n=2930)$

$\begin{array}{lcccc}\text { No } & 311(11) & 193(10) & 118(12) & \text { ref } \\ \text { Yes } & 2143(73) & 1411(74) & 732(72) & 1.2(0.9-1.5) \\ \text { Don't know } & 476(16) & 311(16) & 165(16) & 1.2(0.9-1.6)\end{array}$

An HPV infection is a risk for cervical cancer $(n=2930)$

\begin{tabular}{|c|c|c|c|c|}
\hline No & $215(7)$ & $144(8)$ & $71(7)$ & ref \\
\hline Yes & $2370(81)$ & 1555 (81) & $815(80)$ & $0.9(0.7-1.3)$ \\
\hline Don't know & $345(12)$ & $216(11)$ & 129 (13) & $0.8(0.6-1.2)$ \\
\hline
\end{tabular}

An HPV infection can cause genital warts $(n=2929)$

\begin{tabular}{|c|c|c|c|c|c|}
\hline No & 537 (18) & 354 (18) & $183(18)$ & ref & \\
\hline Yes & $582(20)$ & $389(20)$ & $193(19)$ & $1.0(0.8-1.3)$ & \\
\hline Don't know & $1810(62)$ & $1172(61)$ & $638(63)$ & $1.0(0.8-1.2)$ & 0.63 \\
\hline
\end{tabular}

An HPV infection usually disappears on its own $(n=2930)$

\begin{tabular}{|c|c|c|c|c|c|}
\hline No & $1969(67)$ & $1301(68)$ & $668(66)$ & ref & \\
\hline Yes & $136(5)$ & $80(4)$ & $56(6)$ & $0.7(0.5-1.0)$ & \\
\hline Don't know & $825(28)$ & $534(28)$ & $291(29)$ & $0.9(0.8-1.1)$ & 0.21 \\
\hline \multicolumn{6}{|c|}{ Iareness of CC screening program $(n=2910)$} \\
\hline No & $1421(49)$ & $984(52)$ & $437(43)$ & ref & \\
\hline Yes & $1489(51)$ & $921(48)$ & $568(57)$ & $0.7(0.6-0.8)$ & $<0.001$ \\
\hline
\end{tabular}

Participation of mother in CC screening program $(n=2910)$

\begin{tabular}{|c|c|c|c|c|c|}
\hline No & $670(23)$ & $410(22)$ & $260(26)$ & ref & \\
\hline Yes & $1192(41)$ & 798 (42) & 394 (39) & $1.3(1.1-1.6)$ & \\
\hline Don't know & $1048(36)$ & 697 (37) & 351 (35) & $1.3(1.0-1.5)$ & 0.03 \\
\hline
\end{tabular}

Need to participate in the CC screening program after vaccination $(n=2910)$

$\begin{array}{lcccc}\text { No } & 174(6) & 115(6) & 59(6) & \text { ref } \\ \text { Yes } & 2013(69) & 1346(71) & 667(66) & 1.0(0.7-1.4) \\ \text { Don't know } & 723(25) & 444(23) & 279(28) & 0.8(0.6-1.2)\end{array}$


Table 3 HPV general knowledge amongst all girls participating in our study $(n=2989)$, the Netherlands 2010 (Continued)

\begin{tabular}{|c|c|c|c|c|c|}
\hline \multicolumn{6}{|c|}{ Condoms are not needed anymore once vaccinated $(n=2909)$} \\
\hline No & $2781(96)$ & $1842(97)$ & $939(94)$ & ref & \\
\hline Yes & $22(1)$ & $15(1)$ & $7(1)$ & $1.1(0.5-2.9)$ & \\
\hline Don't know & $106(3)$ & $48(3)$ & $58(6)$ & $0.4(0.3-0.6)$ & $<0.001$ \\
\hline \multicolumn{6}{|c|}{ Girls will use less condoms once vaccinated $(n=2909)$} \\
\hline No & $1526(52)$ & $1076(56)$ & $450(45)$ & ref & \\
\hline Yes & $574(20)$ & $317(17)$ & $257(26)$ & $0.5(0.4-0.6)$ & \\
\hline Don't know & $809(28)$ & $512(27)$ & $297(30)$ & $0.7(0.6-0.9)$ & $<0.001$ \\
\hline \multicolumn{6}{|c|}{ General knowledge score } \\
\hline mean $(95 \% \mathrm{Cl})$ & $5.52(5.48-5.56)$ & $5.51(5.47-5.56)$ & $5.53(5.47-5.59)$ & & 0.62 \\
\hline
\end{tabular}

$\mathrm{CC}=$ cervical cancer.

Missing values are deducted from the total number of girls.

knowledge score. Regardless of vaccination status, as many as $80 \%$ of the girls knew of the relationship between HPV and cervical cancer, which was similar to some other studies (81\% Lenselink $\mathrm{CH}$ et al. [29], 84\% Gerend MA and Shepherd JE [28], 85-93\% Marlow LA et al. [30] program.

In general, only $50 \%$ of the young girls in our study recognised that after an HPV vaccination it is still indicated to participate in the cervical cancer screening program (which takes place from age 30 onwards in the Netherlands). This fact has also been reported by Bowyer HL et al. [31] amongst a group of 15-16 year old girls, where only $47 \%$ was aware cervical screening is still necessary after vaccination. We also found that vaccinated girls were less aware of the fact that vaccination does not protect against all HPV types. The continued importance of cervical screening in the Netherlands has to be emphasised along with the benefits of HPV vaccination. The finding that vaccinated girls report more often that their mothers participate in the cervical cancer screening program seems somewhat contradictory to their lower awareness about this program. Paulussen TG et al. [32] reported that a major part of the population does not make a well thought decision with regard to vaccinations in the regular National Immunization Program). These parents regard vaccination as self-evident. Similarly, this might be so for a part of mothers with regard to participation in screening, which possibly results in less discussion on the topic and thus less knowledge among their daughters.

In our study, only $2-3 \%$ reported that HPV vaccination had changed their sexual behaviour in the first year after vaccination. However, Marlow LA et al. [33] found that one-third of adolescent girls interviewed, thought that HPV vaccination would make girls in general more likely to have unsafe sex. Swedish high-school students did not think it that they themselves would engage in more unsafe sex after HPV vaccination but that other girls might [34]. We found a similar opinion concerning anticipated risk behaviour and condom use. Nearly all girls reported that they would not reduce condom use after HPV vaccination (only $1 \%$ for both groups), but $17 \%$ (vaccinated) and 26\% (unvaccinated) thought other girls would.

There were no significant differences amongst vaccinated and unvaccinated girls for reported condom use with a casual or steady partner. However, sexually active vaccinated girls were more aware of the risk of HPV infection when engaging in unprotected sex. Irrespective of vaccination status, only a quarter of the girls reported to always use condoms with a casual partner and $18 \%$ with a steady partner. In line with Mather T et al. [35] inconsistent or no condom use was reported by $50 \%$ of the girls with a casual partner. Although most of the girls (65\%) in our study reported using other contraceptive methods, the risk of acquiring HPV or another STI through unprotected sex seems to be high in this population. Therefore, early HPV vaccination of 12-year-old girls will considerably decrease the risk of HPV infection at a later and more sexually active age.

With regard to other sexual risk factors we found that among the vaccinated sexually active girls, a somewhat lower mean number of lifetime sexual partners was reported. However, no differences were found for other sexual behavioural characteristics such as age of sexual debut and history of STIs. These results imply that girls who decided not to get vaccinated were not the ones with increased (sexual) risk behaviour. Thus in contrast to screening, where it has been found that more than half of the cervical cancer cases were found in women who did not attend screening, it seems that although these girls are not benefiting from vaccination, they have no disproportional disadvantage compared to vaccinated girls.

This study has several strengths. Firstly, it was a randomly selected, large, nationwide population-based study. Secondly, vaccination status was derived from a national vaccination database instead of being self-reported. Thirdly, we obtained information on the actual vaccination uptake instead of the intention to vaccinate. 
Table 4 HPV transmission knowledge amongst all girls participating in our study $(n=2989)$, the Netherlands 2010

\begin{tabular}{|c|c|c|c|c|c|}
\hline Category & $\begin{array}{l}\text { Total } \\
\mathrm{N}(\%)\end{array}$ & $\begin{array}{c}\text { Vaccinated } \\
\text { n (\%) }\end{array}$ & $\begin{array}{c}\text { Unvaccinated } \\
\text { n (\%) }\end{array}$ & $\begin{array}{l}\mathrm{OR}(95 \% \mathrm{Cl}) \text { for } \\
\text { being vaccinated }\end{array}$ & P-value \\
\hline & $2989(100)$ & $1938(65)$ & $1051(35)$ & & \\
\hline \multicolumn{6}{|c|}{ HPV can be transmitted via; } \\
\hline \multicolumn{6}{|c|}{ Holding hands (no) $(n=2924)$} \\
\hline No & $2884(99)$ & $1882(99)$ & $1002(99)$ & ref & \\
\hline Yes & $40(1)$ & $28(1)$ & $12(1)$ & $1.2(0.6-2.5)$ & 0.53 \\
\hline \multicolumn{6}{|c|}{ Deep throat kissing (no) $(n=2927)$} \\
\hline No & $2622(90)$ & $1711(89)$ & $911(90)$ & ref & \\
\hline Yes & $305(10)$ & $202(11)$ & $103(10)$ & $1.0(0.8-1.3)$ & 0.74 \\
\hline \multicolumn{6}{|c|}{ Skin to skin contact (yes) $(n=2926)$} \\
\hline No & $2646(90)$ & $1727(90)$ & $919(91)$ & ref & \\
\hline Yes & $280(10)$ & $185(10)$ & $95(9)$ & $1.0(0.8-1.3)$ & 0.79 \\
\hline \multicolumn{6}{|c|}{ Stroking partner at genitals (yes) $(n=2927)$} \\
\hline No & $2000(68)$ & $1326(69)$ & $674(66)$ & ref & \\
\hline Yes & $927(32)$ & $587(31)$ & $340(34)$ & $0.9(0.7-1.0)$ & 0.12 \\
\hline \multicolumn{6}{|c|}{ Public toilet (no) $(n=2926)$} \\
\hline No & $2411(82)$ & $1575(82)$ & $836(83)$ & ref & \\
\hline Yes & $515(18)$ & $338(18)$ & $177(17)$ & $1.0(0.8-1.2)$ & 0.89 \\
\hline \multicolumn{6}{|c|}{ Unprotected oral sex (yes) $(n=2928)$} \\
\hline No & $1078(37)$ & $695(36)$ & $383(38)$ & ref & \\
\hline Yes & $1850(63)$ & $1219(64)$ & $631(62)$ & $1.1(0.9-1.2)$ & 0.44 \\
\hline \multicolumn{6}{|c|}{ Unprotected vaginal sex (yes) $(n=2929)$} \\
\hline No & $144(5)$ & $96(5)$ & $48(5)$ & ref & \\
\hline Yes & $2785(95)$ & $1818(95)$ & $967(95)$ & $0.9(0.7-1.3)$ & 0.73 \\
\hline \multicolumn{6}{|c|}{ Unprotected anal sex (yes) $(n=2928)$} \\
\hline No & $865(30)$ & $568(30)$ & $297(29)$ & ref & \\
\hline Yes & $2063(70)$ & $1345(70)$ & $718(71)$ & $1.0(0.8-1.2)$ & 0.81 \\
\hline \multicolumn{6}{|c|}{ Sex with a condom $(n=2927)$} \\
\hline No & $2533(87)$ & $1674(88)$ & $859(85)$ & ref & \\
\hline Yes & $394(12)$ & $238(12)$ & $156(15)$ & $0.8(0.6-1.0)$ & 0.03 \\
\hline \multicolumn{6}{|c|}{ Sharing a spoon or cup (no) $(n=2925)$} \\
\hline No & $2739(94)$ & $1777(93)$ & $962(95)$ & ref & \\
\hline Yes & $186(6)$ & $134(7)$ & $52(5)$ & $1.4(1.0-2.0)$ & 0.05 \\
\hline \multicolumn{6}{|c|}{ Sneezing/coughing (no) $(n=2924)$} \\
\hline No & $2753(94)$ & $1794(94)$ & $959(95)$ & ref & \\
\hline Yes & $171(6)$ & $116(6)$ & $55(5)$ & $1.1(0.8-1.6)$ & 0.48 \\
\hline \multicolumn{6}{|c|}{ Transmission knowledge score } \\
\hline Mean $(95 \% \mathrm{Cl})$ & $7.24(7.19-7.28)$ & $7.24(7.16-7.31)$ & $7.24(7.18-7.29)$ & & 0.99 \\
\hline
\end{tabular}

Missing values are deducted from the total number of girls.

Correct answer is shown in brackets.

Although a limitation of this study was a relatively low response rate (15\%), online surveys/questionnaires, while advantageous, are known for their average lower response rate compared to mail or telephone surveys [36,37]. Similar or lower response rates were obtained in other studies directed to parents of girls targeted for HPV catch-up vaccination
(16\%-24\%) [38] or to participants recruited from Praeventis (7\%) [39]. The response was higher amongst vaccinated than unvaccinated girls $(19 \%$ vs. $11 \%)$ similar to other studies [38]. In order to assess the effect of this response rate we determined if the characteristics of the study population were similar to those of girls in the general population, by 
Table 5 Multivariable analysis amongst all girls participating in our study $(\mathbf{n}=\mathbf{2 9 8 9}$ ), the Netherlands 2010

\section{Risk factor \\ Degree of urbanisation \\ Low (1-1000 inhabitants) \\ High (>1000 inhabitants) \\ Religion}

Univariable $^{a}$

OR $(95 \% \mathrm{Cl})$

No religion

Catholics

Protestant Christian

Other

Alcohol use

No

Yes

\section{Contraception}

No

Yes

Ever had sex

$$
\text { No }
$$

Yes

Awareness of CC screening program

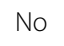

Yes

Participation of mother to CC screening program
No
Yes
Don't know

HPV vaccination protects against all HPV types

No

Yes

Don't know

Girls will use less condoms once vaccinated

No

Yes

Don't know

Condom use is not needed anymore once vaccinated

No

Yes

Don't know ref

$0.8(0.7-0.9)$

ref

$1.2(1.0-1.5)$

$0.4(0.4-0.5)$

$0.3(0.1-0.7)$

ref

$1.4(1.2-1.7)$

ref

$1.5(1.3-1.8)$

ref

$1.2(1.0-1.4)$

ref

$0.7(0.6-0.8)$

ref

$1.3(1.1-1.6)$

$1.3(1.0-1.5)$

ref

$2.2(1.7-2.9)$

$1.4(1.2-1.7)$

ref

$0.5(0.4-0.6)$

$0.7(0.6-0.9)$

ref

$1.1(0.5-2.9)$

$0.4(0.3-0.6)$
Multivariable $^{b, c}$

aOR $(95 \% \mathrm{Cl})$

ref

$0.8(0.7-1.0)$

0.02

ref

$1.2(0.9-1.4)$

0.15

$0.5(0.4-0.6)$

$<0.001$

$0.3(0.1-0.9)$

0.03

ref

$1.3(1.0-1.6)$

0.01

ref

$1.5(1.2-1.9)$

$<0.001$

ref

$0.8(0.6-1.0)$

0.04

ref

$0.7(0.6-0.8)$

$<0.001$

ref

$1.6(1.2-2.0)$

$<0.001$

$1.3(1.0-1.6)$

0.03

ref

$2.4(1.8-3.2)$

$<0.001$

$1.5(1.2-1.8)$

$<0.001$

ref

$0.5(0.4-0.6)$

$<0.001$

$0.7(0.5-0.8)$

0.002

ref

$1.5(0.5-5.6)$

0.5

$0.4(0.2-0.6)$

$<0.001$

CC = cervical cancer.

a 196 cases missing.

${ }^{b}$ Only variables with a P-value less than 0.1 in the univariable analysis were entered.

${ }^{c}$ not significant in multivariable analysis, $(P>0.05)$ (not presented in Table): HPV can be transmitted via a spoon, HPV can be transmitted when using condoms.

comparing our data on education, ethnicity and age of sexual debut. Girls in our study were comparable with respect to sexual debut with another Dutch study [40] but were slightly higher educated than the general Dutch population (59\% vs. $47 \%)$, and were more often not Dutch $(4.7 \%$ vs.
3.3\%) [41]. Nevertheless, our sample size was adequate for the proposed statistical analysis of association with vaccine uptake and the possible influence of differences in ethnicity and education were controlled for in the multivariable analysis. Finally, although we have no indications that our 
results are not applicable to 12-year old girls that are targeted in the routine HPV vaccination program, we cannot rule out that this might be somewhat different. That is, the decision-process towards vaccine uptake may be more influenced by parents/caregivers in this younger age group.

\section{Conclusions}

Routine HPV vaccination in the Netherlands has the potential to reduce the inequity of prevention of cervical cancer. In particular, vaccination uptake was not associated with factors that are known to be associated with non-attendance in the cervical cancer screening program, such as education and ethnicity. Furthermore, most sexual characteristics were comparable amongst both groups indicating that unvaccinated girls are probably not at higher risk of exposure to HPV compared to vaccinated girls. Although in general knowledge could be improved, the large majority of participants knew HPV caused cervical cancer suggesting an informed vaccination choice was made.

\section{Competing interest}

Tjalke Westra (TAW) was involved in this study during his PhD at the University Medical Center Groningen, on an unrestricted educational grant from GlaxoSmithKline (GSK). Currently, TAW is employee of GSK. The other authors declare that they have no conflict of interest.

\section{Authors' contributions}

$\mathrm{KL}, \mathrm{MM}, \mathrm{AT}, \mathrm{HEDM}$ were involved in the data collection, made substantial intellectual contributions to the conceptualization and design of this study and contributed to the content and preparation of this manuscript. MABVDS, SKS, TD, WCMWS, HWN, TAW made substantial intellectual contributions to the conceptualization of this study, the critical reading of the manuscript and final approval of the version to be published. All authors read and approved the final manuscript.

\section{Authors' information}

Madelief Mollers and Karin Lubbers shared first authorship.

\section{Acknowledgements}

We would like to thank the following persons:

All girls who participated in the study.

Petra Oomen, from Regional Coordination of Programs/Purchase, Storage and Distribution (RCP/IOD), Centre for Infectious Disease Control, National Institute for Public Health and the Environment (RIVM), Bilthoven, the Netherlands, for providing the individual data from the national vaccination registers (Praeventis)

Nynke Koelma, who was involved in the initial design of the study.

\section{Author details}

${ }^{1}$ Epidemiology and Surveillance, Centre for Infectious Disease Control, National Institute for Public Health and the Environment (RIVM), Bilthoven, The Netherlands. ${ }^{2}$ Pathology, VU University Medical Center (VUmc), Amsterdam, The Netherlands. ${ }^{3}$ Department of Obstetrics and Gynecology, University of Groningen, University Medical Center Groningen, Groningen, The Netherlands. ${ }^{4}$ Department of Medical Microbiology, Molecular Virology Section, University of Groningen, University Medical Center Groningen, Groningen, The Netherlands. ${ }^{5}$ Julius Center for Health Sciences and Primary Care, University Medical Center Utrecht, Utrecht, The Netherlands. ${ }^{6}$ Department of Medical Microbiology, University Medical Center Groningen, P.O. Box 30.001, 9700 RB Groningen, The Netherlands.

Received: 4 September 2013 Accepted: 18 March 2014

Published: 28 March 2014

\section{References}

1. Baseman JG, Koutsky LA: The epidemiology of human papillomavirus infections. J Clin Virol 2005, 32(Suppl 1):16-24.

2. Koutsky L: Epidemiology of genital human papilloma virus infection. Am J Med 1997, 102(Suppl 5A):3-8.

3. Brown DR, Shew ML, Qadadri B, Neptune N, Vargas M, Tu W, Juliar BE, Breen TE, Fortenberry JD: A longitudinal study of genital human papillomavirus infection in a cohort of closely followed adolescent women. J Infect Dis 2005, 191:182-192.

4. Ho G, Bierman R, Beardsley L, Chang CJ, Burk RD: Natural history of cervicovaginal papillomavirus infection in young women. $N$ Engl J Med 1998, 338:423-428.

5. Moscicki A-B, Schiffman M, Kjaer S, Villa LL: Chapter 5: updating the natural history of HPV and anogenital cancer. Vaccine 2006, 24(Suppl 3):42-51.

6. zur Hausen H, Gissmann L, Steiner W, Dippold W, Dreger J: Human papilloma viruses and cancer. Bibl Haematol 1975, 43:569-571.

7. Castellsagué X, Muñoz N, Pitisuttithum P, Ferris D, Monsonego J, Ault K, Luna J, Myers E, Mallary S, Bautista OM, Bryan J, Vuocolo S, Haupt RM, Saah $A$ : End-of-study safety, immunogenicity, and efficacy of quadrivalent HPV (types 6, 11, 16, 18) recombinant vaccine in adult women 24-45 years of age. Br J Cancer 2011, 105:28-37.

8. Lehtinen M, Paavonen J, Wheeler CM, Jaisamrarn U, Garland SM, Castellsagué X, Skinner SR, Apter D, Naud P, Salmerón J, Chow S-N, Kitchener H, Teixeira JC, Hedrick J, Limson G, Szarewski A, Romanowski B, Aoki FY, Schwarz TF, Poppe WJ, De Carvalho NS, Germar MJV, Peters K, Mindel A, De Sutter P, Bosch FX, David M-P, Descamps D, Struyf F, Dubin G: Overall efficacy of HPV-16/18 AS04-adjuvanted vaccine against grade 3 or greater cervical intraepithelial neoplasia: 4-year end-of-study analysis of the randomised, double-blind PATRICIA trial. Lancet Oncol 2012, 13:89-99.

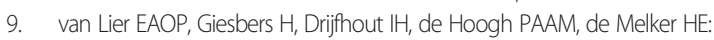
Vaccinatiegraad Rijksvaccinatieprogramma Nederland: Verslagjaar 2012, RIVM rapport nr. 201001001. Bilthoven: Rijksinstituut voor Volksgezondheid en Milieu; 2012.

10. Brabin L, Roberts SA, Stretch R, Baxter D, Elton P, Kitchener H, McCann R: A survey of adolescent experiences of human papillomavirus vaccination in the Manchester study. Br J Cancer 2009, 101:1502-1504.

11. Chao C, Velicer C, Slezak JM, Jacobsen SJ: Correlates for completion of 3-dose regimen of HPV vaccine in female members of a managed care organization. Mayo Clin Proc 2009, 84:864-870.

12. Bulk S, Visser O, Rozendaal L, Verheijen RH, Meijer CJ: Cervical cancer in the Netherlands 1989-1998: decrease of squamous cell carcinoma in older women, increase of adenocarcinoma in younger women. Int J Cancer 2005, 113(6):1005-1009.

13. Rebolj M, van Ballegooijen M, Berkers LM, Habbema D: Monitoring a national cancer prevention program: successful changes in cervical cancer screening in the Netherlands. Int J Cancer 2007, 120(4):806-812.

14. van Leeuwen AW, de Nooijer P, Hop WC: Screening for cervical carcinoma. Cancer 2005, 105:270-276.

15. van der Aa MA, Schutter EM, Looijen-Salamon M, Martens JE, Siesling S: Differences in screening history, tumour characteristics and survival between women with screen-detected versus not screen-detected cervical cancer in the east of The Netherlands, 1992-2001. Eur J Obstet Gynecol Reprod Biol 2008, 139:204-209.

16. Bulk S, Visser O, Rozendaal L, Verheijen $\mathrm{RH}$, Meijer CJ: Incidence and survival rate of women with cervical cancer in the Greater Amsterdam area. Br J Cancer 2003, 89:834-839.

17. Dillard JP: An application of the integrative model to women's intention to be vaccinated against HPV: implications for message design. Health Commun 2011, 26:479-486

18. Kang HS, Moneyham L: Attitudes toward and intention to receive the human papilloma virus (HPV) vaccination and intention to use condoms among female Korean college students. Vaccine 2010, 28:811-6.

19. Kim HW: Knowledge about human papillomavirus (HPV), and health beliefs and intention to recommend HPV vaccination for girls and boys among Korean health teachers. Vaccine 2012, 30:5327-5334.

20. Tiro JA, Tsui J, Bauer HM, Yamada E, Kobrin S, Breen N: Human papillomavirus vaccine use among adolescent girls and young adult women: an analysis of the 2007 california health interview survey. $J$ Womens Health 2012, 21:656-665.

21. Kessels SJM, Marshall HS, Watson M, Braunack-Mayer AJ, Reuzel R, Tooher RL: Factors associated with HPV vaccine uptake in teenage girls: a systematic review. Vaccine 2012, 30:3546-3556

22. van Lier A, Oomen P, de Hoogh P, Drijfhout I, Elsinghorst B, Kemmeren J, Conyn-van Spaendonck M, de Melker H: Praeventis, the immunisation 
register of the netherlands: a tool to evaluate the national immunisation program. Euro Surveill 2012, 17(17).

23. Helsinki declaration. http://www.wma.net/en/30publications/10policies/b3

24. Knol F: From high to low; from low to high: the social development of districts between 1971 and 1995 [in dutch]. The hague; the Netherlands institute for social research. 1998.

25. Steens A, Wielders CC, Bogaards JA, Boshuizen HC, de Greeff SC, de Melker HE: Association between human papillomavirus vaccine uptake and cervical cancer screening in the Netherlands: implications for future impact on prevention. Int J Cancer 2013, 132:932-943.

26. Grabenstein JD: What the world's religions teach, applied to vaccines and immune globulins. Vaccine 2013, 31(16):2011-2023.

27. White A: Theological opposition to inoculation, vaccination, and the use of anæesthetics. A history of the warfare of science with theology in Christendom. Chapter 13. SAGE software, albany, oregon. New York: D. Appleton and Company; 1996. Accessible at: http://vserver1.cscs. Isa.umich.edu/ crshalizi/ White/.

28. Gerend MA, Shepherd JE: Correlates of HPV knowledge in the era of HPV vaccination: a study of unvaccinated young adult women. Women Health 2011, 51:25-40.

29. Lenselink CH, Schmeink CE, Melchers WJ, Massuger LF, Hendriks JC, van Hamont D, Bekkers RL: Young adults and acceptance of the human papillomavirus vaccine. Public Health 2008, 122:1295-1301.

30. Marlow LA, Zimet GD, McCaffery KJ, Ostini R, Waller J: Knowledge of human papillomavirus (HPV) and HPV vaccination: an international comparison. Vaccine 2012, 31:763-769.

31. Bowyer HL, Marlow LA, Hibbitts S, Pollock KG, Waller J: Knowledge and awareness of HPV and the HPV vaccine among young women in the first routinely vaccinated cohort in England. Vaccine 2013, 31:1051-1056.

32. Paulussen TG, Hoekstra F, Lanting Cl, Buijs GB, Hirasing RA: Determinants of Dutch parents' decisions to vaccinate their child. Vaccine 2006, 24(5):644-651.

33. Marlow LAV, Forster AS, Wardle J, Waller J: Mothers' and adolescents' beliefs about risk compensation following HPV vaccination. J Adolesc Health 2009, 44:446-451.

34. Höglund AT, Tydén T, Hannerfors AK, Larsson M: Knowledge of human papillomavirus and attitudes to vaccination among Swedish high school students. Int J STD AIDS 2009, 20:102-107.

35. Mather T, McCaffery K, Juraskova I: Does HPV vaccination affect women's attitudes to cervical cancer screening and safe sexual behaviour? Vaccine 2012, 30:3196-3201

36. Monroe $M$, Adams D: Increasing response rates to web-based surveys. Journal of Extension [Online] 2012, 50(6). Article 6TOT7.

37. Bergeson SC, Gray J, Ehrmantraut LA, Laibson T, Hays RD: Comparing Webbased with mail survey administration of the consumer assessment of healthcare providers and systems (CAHPS) clinician and group survey. Prim Health Care 2013, 3:1000132.

38. Gefenaite G, Smit M, Nijman HW, Tami A, Drijfhout IH, Pascal A, Postma MJ, Wolters BA, van Delden JJ, Wilschut JC, Hak E: Comparatively low attendance during human papillomavirus catch-up vaccination among teenage girls in the Netherlands: insights from a behavioral survey among parents. BMC Public Health 2012, 12:498.

39. van Keulen HM, Otten W, Ruiter RA, Fekkes M, van Steenbergen J, Dusseldorp E, Paulussen TW: Determinants of HPV vaccination intentions among Dutch girls and their mothers: a cross-sectional study. BMC Public Health 2013, 13:111.

40. de Graaf H, Meijer S, Poelman J: Sex Under 25 [in Dutch]. Delft, the Netherlands: Eburon Publishers, Rutgers Nisso Groep; 2005.

41. Statistics Netherlands. http://statline.cbs.nl/StatWeb.

doi:10.1186/1471-2458-14-288

Cite this article as: Mollers et al:: Equity in human papilloma virus vaccination uptake?: sexual behaviour, knowledge and demographics in a cross-sectional study in (un)vaccinated girls in the Netherlands. BMC Public Health 2014 14:288.

\section{Submit your next manuscript to BioMed Central and take full advantage of:}

- Convenient online submission

- Thorough peer review

- No space constraints or color figure charges

- Immediate publication on acceptance

- Inclusion in PubMed, CAS, Scopus and Google Scholar

- Research which is freely available for redistribution

Submit your manuscript at www.biomedcentral.com/submit 